\section{Hiperplasia gingival por obstrucción de vías respiratorias altas}

Gingival hyperplasia by upper airway obstruction

\section{Resumen}

El efecto de la respiración bucal consiste en la introducción de aire frío, seco y cargado de polvo en la boca y la faringe, al perderse la función de calentamiento, humedificación y filtrado del aire que entra por la nariz incrementa la irritación de la mucosa bucal y faríngea. Se presenta el caso de una paciente de sexo femenino de 15 ańos de edad que acude a consulta de periodoncia presentando aumento de volumen y enrojecimiento gingival en el sector antero superior por obstrucción de vías respiratorias altas causada por desviación del tabique nasal derecho, hipertrofia de cornetes y sinusitis del maxilar. Se plantea: características clínicas, diagnóstico, y plan de tratamiento. Luego del tratamiento de la enfermedad periodontal, la paciente será transferida al hospital para realizarse septoplastía por recomendación del especialista.

\begin{abstract}
The effects of mouth breathing are the introduction of cold air, dry and dusty in the mouth and pharynx, the lost functions of heating, humedificacion and filtering the air entering the nose increases the oral mucosa irritation and pharyngeal. A case of a female patient 15 years old who comes for consultation of Periodontology with increase in volume and gingival redness in the upper anterior sector of upper airway obstruction caused by deviated septum right turbinate hypertrophy and maxillary sinusitis. This raises the clinical features, diagnosis, and treatment plan. After treatment of periodontal disease, patients will be transferred to hospital for a recommendation from the specialist septoplasty.
\end{abstract}

\section{Introducción}

El hombre nace condicionado para respirar por la nariz y alimentarse por la boca, al romperse ese mecanismo fisiológico se afecta el crecimiento y desarrollo, no sólo facial, sino general. La respiración bucal se considera normal solo cuando se realiza bajo esfuerzos físicos muy grandes. Los efectos inmediatos de la respiración bucal consisten en la introducción de aire frío, seco y cargado de polvo en la boca y la faringe. ${ }^{1}$ Se pierden las funciones de calentamiento, humidificación y filtrado del aire que entra por la nariz, con el consiguiente incremento de la irritación de la mucosa bucal y faríngea, siendo pobre la cantidad de oxígeno que pasa a la sangre. ${ }^{2}$ Los que respiran por la boca por obstrucción, son aquellos que presentan desviación del tabique nasal, cornetes agrandados, inflamación crónica y congestión de la mucosa faríngea, alergias e hipertrofia amigdalina. Una de las consecuencias seria la llamada hiperplasia gingival.

La hiperplasia gingival es una lesión benigna que consiste en un aumento del número de células de la encía, ya que se produce un incremento excesivo de fibroblastos y de la síntesis de colágeno. ${ }^{3}$ Suele aparecer con respuesta inflamatoria asociada y sobrecrecimiento de las papilas interdentales. La hiperplasia gingival aparece como síntoma de algunas enfermedades, además puede darse por anomalías congénitas, cabe destacar la acción de algunos fármacos ${ }^{4}$ en la producción de esta enfermedad como los bloqueadores de canales de calcio, anticonvulsivos y ciclosporina inmunosupresora. Por otro lado, la acumulación de placa bacteriana es un factor agravante en la evolución de la hiperplasia gingival. Por último, el tratamiento puede llevarse a cabo de forma conservadora, mejorando la higiene, eliminando los posibles fármacos o factores irritativos causantes. En los casos más graves, puede ser necesario recurrir a tratamiento quirúrgico (gingivectomía y gingivoplastia). ${ }^{3}$

El propósito de reporte de este caso clínico es demostrar la importancia de la participación multidisciplinaria con la finalidad de ofrecer una mejor calidad de vida al paciente.

\section{Caso clínico}

\section{Anamnesis}

Paciente de sexo femenino de 15 años de edad, procedente de Ayacucho, se

\section{Ana Díaz Soriano ${ }^{1}$ \\ Víctor Lévano Torres ${ }^{2}$ \\ Shamila Pastor Yataco ${ }^{3}$ \\ Arturo Vallejos Pulido ${ }^{3}$ \\ Lizbeth Huamanyauri Gonzales ${ }^{3}$}

Docente Departamento Académico de Estomatología Biosocial

2 Docente Departamento Académico Médico Quirúrgico

3 Alumnos del 3er año de Odontología de la UNMSM

Correspondencia:

Shamila Pastor Yataco

Dirección: Calle Los Zorzales 295

Bellavista Callao Perú

Teléfono: 4645482

E-mail: belldandy324@hotmail.com

Palabras clave: hiperplasia gingival, respiración oral, gingivoplastía

Keywords: gingival hyperplasia, oral breathing, gingivoplasty

presenta a la consulta de pregrado de periodoncia de la Universidad Nacional Mayor de San Marcos, manifestando sangrado gingival espontáneo y profuso durante el cepillado y la masticación de alimentos fibrosos. Paciente refiere no haber perdidodientes que se movían, no usar aparato de prótesis, ni haber recibido tratamiento de ortodoncia.

\section{Examen clínico}

$\mathrm{Al}$ examen clínico oral se reportó inflamación con aumento de volumen en las papilas interdentales entre las piezas $1.3 \mathrm{y}$ 2.3 , pseudobolsas con una profundidad promedio de $5 \mathrm{~mm}$, encías eritematosas de textura lisa, consistencia fluctuante y sangrado espontáneo en zona antero superior. Además se detectó inflamación gingival leve en las zonas postero superior e inferior (Fig. 1) y obstrucción de vías respiratorias altas por lo que se realiza la interconsulta al otorrinolaringólogo, quien diagnostica desviación de tabique nasal hacia la derecha, hipertrofia de cornetes y sinusitis en el maxilar a través del examen clínico y examen topográfico axial coronal (Fig. 2). El especialista recomienda primero realizar el tratamiento de la enfermedad periodontal. 


\section{Diagnóstico}

Hiperplasia gingival asociada a respiración bucal por desviación de tabique nasal e hipertrofia de cornetes.

\section{Plan de tratamiento, evolución y resultados}

El tratamiento comprende Fases I, II y III. Se inicia con la Fase I que comprende instrucciones de higiene oral con evaluaciones semanales de control de placa, raspado y alisado radicular, profilaxis, y terapia antimicrobiana con clorhexidina al $0.12 \%$ dos veces al día.

Luego de cuatro semanas de tratamiento, las papilas interdentales de la zona antero superior mostraron disminución de volumen, color rosado con halos rojos, consistencia dura, sangrado leve y sin dolor a la palpación (Fig. 3).

Se decidió continuar con la fase quirúrgica que consistió en gingivoplastía de las papilas interdentales de la zona antero superior con la finalidad de devolver el contorno gingival fisiológico que permita un mejor control de placa y le devuelva la estética, además del curetaje por colgajo.
La fase de mantenimiento consistió en una revisión post cirugía luego de una y cuatro semanas (Fig. 4).

\section{Discusión}

Existen diferentes causas por las cuales un paciente puede presentar hiperplasia gingival. Estas causas pueden ser por administración de fármacos, ${ }^{4}$ por efecto hormonal durante el embarazo o la pubertad y en pacientes con factores predisponentes como respiradores bucales. $^{3}$

Una hiperplasia en el embarazo solo se puede tratar con raspado y alisado radicular eliminando los irritantes locales y disminuyendo el volumen gingival sin necesidad de realizar la fase quirúrgica. ${ }^{5}$ La causa también puede radicar en la administración de fármacos como las ciclosporina inmunosupresora en pacientes con transplante renal, ${ }^{6}$ bloqueadores de calcio como el nifedipino, ${ }^{7,8} \mathrm{y}$ las hidantoínas que junto con la respiración bucal y mala higiene oral favorecen la hiperplasia gingival. ${ }^{\text {? }}$

La paciente reportada en el caso presenta desviación del tabique nasal e hipertrofia de cornetes el cual obstruye las vías respiratorias altas provocando la respiración bucal. En interconsulta con otorrinolaringología, da como alternativa de tratamiento realizar primero la gingivoplastía y luego la septoplastía.

Durante el tratamiento se eliminaron los irritantes locales (controlando placa bacteriana), se observó disminución del tamaño y sangrado de las papilas interdentales, cambio de color, pero el agrandamiento aún era notorio, por lo que se realizó la remodelación del margen gingival a través de la gingivoplastía, además se realizo curetaje por colgajo, logrando la recuperación del tejido gingival a niveles normales de anatomía y coloración

\section{Conclusiones}

El presente caso se trata de una hiperplasia gingival en una paciente de 15 años de edad, cuya causa estuvo asociada a la respiración bucal por desviación de tabique nasal e hipertrofia de cornetes.

La terapia de control de placa bacteriana y gingivoplastia papilar logró la recuperación del tejido gingival afectado.
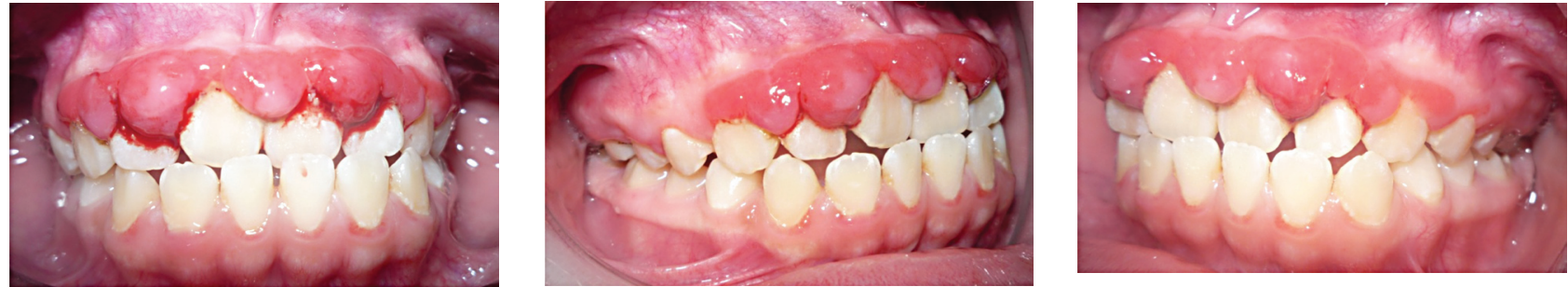

Fig. 1. Vista preoperatorio frontal, lateral derecha e izquierda.

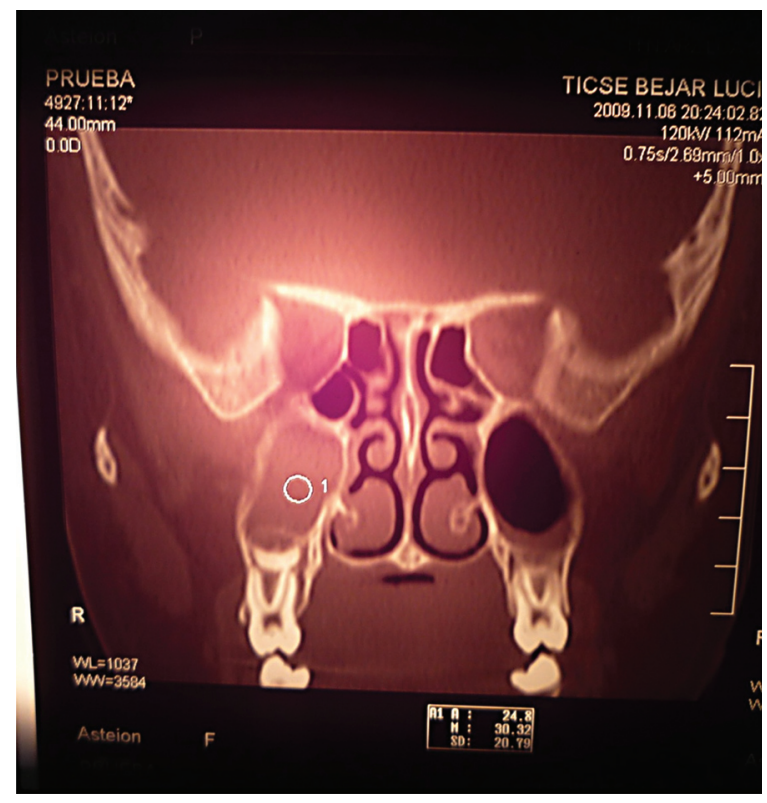

Fig. 2. Tomografía axial coronal.

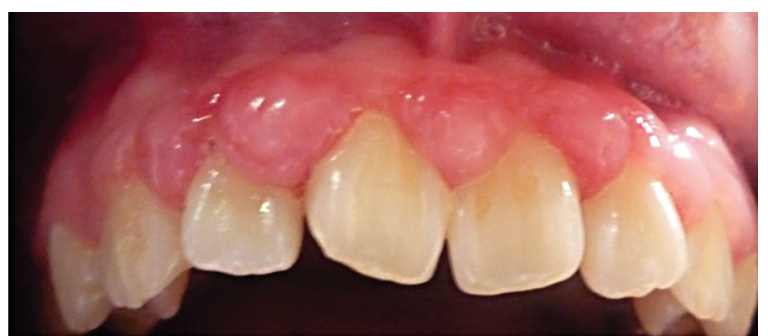

Fig. 3. Vista frontal 4ta semana de tratamiento.

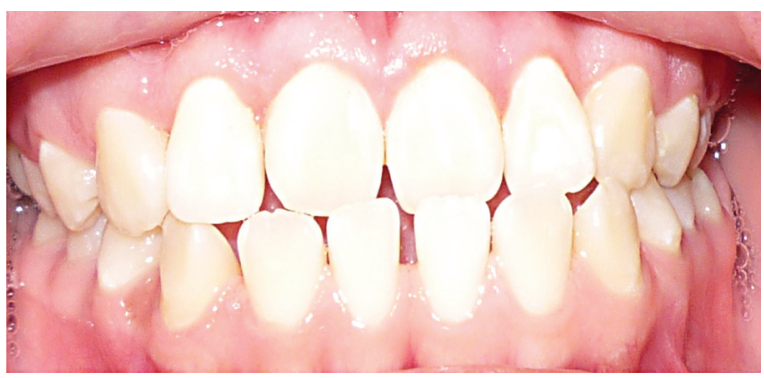

Fig. 4. Vista frontal luego de 4 semanas post quirúrgico. 


\section{Referencias bibliográficas}

1. Lydia B, Moraima P, Castillo C, Rodríguez C, Duque H. Habito de reexpiación bucal en niños. Rev Cubana de ortodoncia 2001; 16(1):47-53.

2. Parra Y. El paciente respirador bucal una propuesta para el estado Nueva Esparta 1996-2001. Rev Acta Odontológica Venezolana 2004; 42(2).

3. Newman M, Takey H, Carranza F. Periodontología Clínica.9na ed. México. Mac Graw Hill. 2004:297-308
4. Costa P, Silvina R, Gasparini E, Diego O, Valsecia A, Mabel E. Drug-induced gingival hyperplasia in the north-eastern Argentina. Rev. Asoc. Odontol. Argent 2004;92(3):267-271.

5. Larez L, Benavides Y, Henríquez Y, Moreno S. Lesiones bucales vistas en la embarazada. Rev Obstet Ginecol Venez 2005;65(1):9-11.

6. De la Rosa G, Mongragón P, Irigoyen $\mathrm{C}$, Bustamante R. Lesiones bucales en un grupo de pacientes con transplante renal. Med. Oral Patol, Oral Cir. Bucal 2005; 10 (3)
7. Díaz C, Arévalo T, Fonseca R. Agrandamiento gingival inducido por nifedipina. Reporte de um caso. Duazary 2009; 6(1): 51-59.

8. Algozain A. et al. Crecimiento gingival por el uso de ciclosporina $\mathrm{A}$ $\mathrm{y}$ nifedipino en un paciente con transplante renal. Rev Cub Med Mil 2008; 37(2).

9. Morales C. Patologías bucodentales y alteraciones asociadas prevalentes en una población de pacientes con paralisis cerebral infantil. Rev Acta Odontol Venezolana 2008:46(1):52-55.

Fecha de recepción: 18 de diciembre 2009

Fecha de aprobación: 5 de enero 2010 